acknowledgment, let alone explanation, of the philosophical debate about this crucial point.

As Dr Higgs says, the principle of double effect deserves a mention in this report. Once it is accepted that there is a distinction in moral terms between the active and passive taking of life one can produce an elaborate and well reasoned justification of our present easy conscience with withdrawing treatment while holding out against active intervention to terminate life. If this is not accepted one has to consider either that active euthanasia, like the withdrawal of treatment, can be morally acceptable or that withdrawal of treatment, like active intervention to terminate life, is morally wrong. Both are attitudes that doctors will find difficult to integrate with current practice.

It is a pity that the report did not take the opportunity to explore the important philosophical questions behind this distinction. The distinction may be a valid one in moral terms, but it would have been a better report had it contained the arguments behind this. As it is one could be left with the suspicion that this is a particular can of worms that the working party was not keen to open up lest it should lead to some uneasy answers.

J P'WIGHT

Northern (ieneral Hespital,

Sheificld S5 $7 \mathrm{AU}$

\section{Organs for transplantation}

Professor Geoffrey D Chisholm (21 May, p 1419) discusses the "required request" and "routine inquiry" methods of obtaining organs for transplantation.

Reservations about "beating heart donors" originate from the 1979 memorandum to the 1976 report of the conference of medical roval colleges. The report recommended that absence of response to tests for brain stem death may indicate a hopeless prognosis and is a helpful guide to discontinuing artificial ventilation. The memorandum, however, incorrectly equated that state with death itself on the basis that "by then all functions of the brain have totally and irreversibly ceased." There is ample evidence that this latter deduction was, and remains, untrue.

Relatives who refuse permission for organs to be removed because the patient "has already been through enough" may have greater insight into the situation than the doctors wanting to harvest the organs. The explanation of Professor Chisholm's observation that the results of kidney transplantation from cadavers have come closer to the results with live donations is that the cadavers have come closer to being live donors. We must distinguish clearly between those donors who will be dead after life support is stopped (from whom kidneys and eyes may usefully be taken) and those who are nearly dead (from whom hearts, lungs, livers, and pancreas can be obtained while they remain ventilated, perfused, and reactive). Relatives should be given the opportunity to give or withhold consent for either circumstance.

Some anaesthetists recognise the need to anaesthetise such "cadavers" for surgery and to paralyse them, so the option of anaesthesia for the donor should also be offered specifically to donors or relatives of donors. Prior consent from donors is by a donor card, and this should be rephrased to allow consent to be given for removal of organs either before or after withdrawal of life support. Such consent should be countersigned by the doctor who has explained the procedure.

Professor Chisholm is wrong when he writes that "a patient not on a respirator can never be a donor." It is not necessary to be a "beating heart" donor for one's corneas and kidneys to be of use. People who have deleted all except eves and kidneys from the organs listed on their donor cards in the hope that this will ensure that they are not used as "beating heart" donors have no such security at present. This wish should be included explicitly on the donor card.

David J Hil.L.

Addenbrexke's Hospital

Cambridge CB2 2QO

\section{Medical education}

Dr H J N Andreyev (7 May, p 1326) should have been taught basic scientific principles while he was at secondary school. I was fortunate in being taught under HE Armstrong's "heuristic" method. Instead of being told to "verify the gas laws" I was given apparatus and told how to measure the effect of change of temperature on the pressure of a gas confined to a constant volume and of changes of pressure on its volume when kept at a constant temperature. In such ways I learnt to do reproducible experiments, to distinguish a dependent from an independent variable, and to consider the variability of observation and the dangers of coming to a conclusion on inadequate data.

When I came to the wards and clinics I had to amass my own data in a world in which the data were changing constantly. The rules which seemed to apply to one patient might not apply to another, or even to the same patient at a different time. I had to amass empirical experience. Tenderness at McBurney's point usually suggests appendicitisbut once when it appeared without any of the other signs of appendicitis it turned out to be caused by a hydronephrosis which had ruptured while the patient was at rest in bed. I know of no general scientific principles which will allow you to make these distinctions. If there were any, life would be much easier.

Doctors are technicians; peculiar ones, I agree, and with a remarkable field of work. My contemporaries were fortunate, for a registrar's round rarely had more than five or six students around the bed. Grand rounds were show occasions at which only the clinical clerk had much of a look in. Practical teaching is usually better given by juniors than by consultants, unless the consultant has a special delight in teaching or acting a part.

(iEORGE DISCOMBE

Havwards Heath

W's Sussex RH16 IHH

\section{Obstructive uropathy}

Dr Kathleen Lyons and others (28 May, p 1517) state that dilatation is the hallmark of obstruction of the urinary tract. While this is widely accepted, it is not true.

Ormand in his report of retroperitoneal fibrosis comments on the almost normal appearance of the renal pelvis in a man with acute anuria, ' and this has been noted by other authors.' Similar appearances have been noted in obstruction by carcinoma. Lalli refers to the common appearance of undilated pelvicaliceal systems in retroperitoneal fibrosis. Davies suggested that the pelvicaliceal system in acute obstruction was not dilated, and this has been confirmed by recent ultrasound studies." A range of appearances has been described in obstruction caused by various diseases. " Appreciable dilatation of the pelvicaliceal system and ureters may be present (especially in pregnancy) with no obstruction."

Ultrasound is not good at detecting dilatation of the pelvicaliceal system and is subject to false positive and false negative errors. "'" Enthusiasm for a new technique which is painless, easy, and relatively fast have made ultrasound investigations popular. Failure to follow a sequential series of investigations has been a factor.
In all medical practice it is important to understand the disease. Ultrasound is an imaging technique which shows anatomy and not physiology. It was predictable that it would be less than perfect in investigating many cases of obstruction. The duty of the radiologist is to understand the disease process and choose the most suitable imaging technique or sequence to elucidate the problem. It is too easy for ultrasound studies to become routine examinations which do not contribute to the diagnosis. ${ }^{1}$

PETER DAVIFS

Department of Radiology,

City Hospital,

Nottingham $\mathrm{N}(\mathrm{B} 10)+\mathrm{F}(\mathrm{i}$

I ()rmand JK. Bilateral ureteric ohstruction due to envelopment and compression by an inflammatory retroperitoneal process. 7 l'rol 1948;59: 1072-9.

2 Saxton HM, Kilpatrick FR, Kinder CM, Lessof MN, McHardy Young S, W'ardle DFH. Retroperiteneal fibrosis. $2.7 . \mathrm{Med}$ 1969:38:159-81.

SElliott S, Davies P. The urographic appearances of ureteric obstruction secondary to bladder carcinoma. Clin Radiol 1986:37:495-8

+ Lalli $\mathrm{AF}$. Retroperitoneal fibrosis and inapparent obstructive uropathy. Radiolog, 1977:122:339-42

Davie P. Lrographic appearances in renal failure due 10 inerape intraluming

6 Hill MC, Rich JL, Mordiat JG, Finder (CA. Sonography versus excretion urography in acute flank pain. American foumal of Rocingenology 1985;144:1235-8

Laing $\mathrm{F} C$, Jeffrey $\mathrm{BR}$, Wing VW. Ultrasound versus excretion urography in acute flank pain. Radiologv 1985:154:613-6.

8 Minford J. Davies P. The urographic appearances in acute and chronic retroperitoneal fibrosis. Clin Radiol 1984;38:51-7

Daties P. Ultrasound dees not diagnose ureteric obstruction. $7 R$ Sir Med in press

10 Talner L, Scheible W' Lillenbogen PM, Berk CH, Gosink BB How accurate is ultrasonography in detecting hydronephrosis in azotemic patients? ['rol Radiol 1981:3:1-6.

11 Amis IES. Cronan JJ, Pfister RC, Yoder IC. Ultrasonic in accuracies in diagnosing renal obstruction. Erologv 1982;19. $101-5$

12 Anonvmous. Diagnosing obstruction in renal failure. Lancel $198+$ :ii: $848-9$.

13 Mindel S. The full potential of ultrasound. Br.Med F 1988:296:

\section{Drug and alcohol misuse in pregnancy}

Dr Nabeel D Sulaiman and others (28 May, p 1500) found that $2 \%$ of a sample of 901 women in early pregnancy consumed $100 \mathrm{~g}$ or more absolute alcohol a week. The psychiatric department at Guy's Hospital recently set up a service within the antenatal clinic for pregnant drug addicts. To gauge some idea of the size of the problem we decided to carry out a random screening. On their initial visit to the antenatal clinic 218 pregnant women were asked to give urine samples. The purpose of the test was explained and verbal permission sought from each patient. Only two women refused; one of them later consented but no drugs or alcohol were found in her urine sample.

Of the remaining 216 women, four had positive results for alcohol, two for opiates, and one for benzodiazepine. Apart from one woman with epilepsy who was taking prescribed phenobarbitone, no other sedative or stimulant drug was detected in the urine samples. All four women who showed alcohol in their urine were over 30 . The urine test was sensitive to a blood alcohol concentration of $2 \cdot 2 \mathrm{mmol} / 1(10 \mathrm{mg} / 100 \mathrm{ml})$. Thus women who consumed alcohol before or during lunch or had drunk heavily the night before were detected. These patients may correspond to $\mathrm{Dr}$ Sulaiman and others' category of women who consume 10 or more standard drinks $(100 \mathrm{~g})$ a week. If so our findings are nearly identical. Only one of the four women agreed to be interviewed by a psychiatrist, and she claimed abstinence despite her results.

Both women with opiates detected in their urine were under 30 . They both accepted treatment and were using less than $20 \mathrm{mg}$ heroin a day. One smoked and the other injected heroin intra- 